\title{
Low Reverse T3: A Reliable, Sensitive and Specific in Diagnosis of Central Hypothyroidism*
}

\author{
Sarah Exley¹, Sonal Banzal1, Udaya Kabadi1,2* \\ ${ }^{1}$ Broadlawns Medical Center, Des Moines, Iowa, USA \\ ${ }^{2}$ University of Iowa, Iowa City, Iowa, USA \\ Email: sexley@broadlawns.org, soanbanzal@gmail.com, *ukabadi@gmail.com
}

How to cite this paper: Exley, S., Banzal, S. and Kabadi, U. (2021) Low Reverse T3: A Reliable, Sensitive and Specific in Diagnosis of Central Hypothyroidism. Open Journal of Endocrine and Metabolic Diseases, 11, 137-143.

https://doi.org/10.4236/ojemd.2021.117011

Received: June 15, 2021

Accepted: July 19, 2021

Published: July 22, 2021

Copyright $\odot 2021$ by author(s) and Scientific Research Publishing Inc. This work is licensed under the Creative Commons Attribution International License (CC BY 4.0).

http://creativecommons.org/licenses/by/4.0/

\begin{abstract}
Background: Low free T4 and normal/low TSH concentrations are often noted in clinical practice and denote presence of "Euthyroid Sick Syndrome" or Central Hypothyroidism. However, accurate diagnosis is difficult even with determination of free T3 being low/normal in both. Repeated determination of these tests may help differentiate between these disorders. Objective: Evaluation of reverse T3 to differentiate between "Euthyroid Sick Syndrome" and Central Hypothyroidism. Subjects and Methods: Free T3 and Reverse T3 were determined as "add on" tests using previously drawn blood samples of 78 consecutive adults showing low free T4, $0.80 \pm 0.02$ and low/normal TSH, $1.29 \pm 0.40$ [normal ranges, $0.89-1.70 \mathrm{mcg} / \mathrm{dl} ; 0.45-4.67$ $\mathrm{uU} / \mathrm{ml}$ ]. Free T4, free T3, TSH and reverse T3 levels were also determined in age-matched 35 healthy volunteers and reassessed in study group. Statistical analyses for comparisons were conducted between groups. All data are reported as Mean \pm SEM. Results: Reverse T3 established two distinct groups: 1) subnormal concentrations, $8.31 \pm 0.52$ [range, $11-14 \mathrm{ng} / \mathrm{dl}$ ]; 2) supernormal levels; $32 \pm 4$ [normal Range 12 - 26]. Free T3 concentrations were subnormal or normal, $1.6-2.9$ [normal range, $2.3-4.2 \mathrm{ng} / \mathrm{ml}$ ] in individuals amongst both groups. On reassessment after 3 - 6 weeks, free T4, free T3, TSH and reverse T3 normalized in group with normal or elevated reverse T3 indicating recovery from "Euthyroid Sick Syndrome" whereas free T4 and reverse T3 remained subnormal in the other group suggesting presence of Central Hypothyroidism. Conclusion: Reverse T3 is a reliable laboratory test differentiating between Central Hypothyroidism and "Euthyroid Sick Syndrome" in subjects with low free T4 and low/normal TSH levels.
\end{abstract}

*The data was presented in part at annual meeting of American Thyroid Association in 2019. Short call, poster 36 . 


\section{Keywords}

Euthyroid Sick Syndrome, Central Hypothyroidism, Reverse T3, Free T4, Free T3, TSH

\section{Introduction}

Euthyroid sick syndrome, also known as non thyroidal illness refers to changes seen in in vitro thyroid function tests in presence of acute or chronic illness as well as during starvation and carbohydrate deprivation [1]-[15]. Abnormal concentrations of thyroid hormone and Thyroid stimulating hormone [TSH] are attributed to altered thyroid hormone metabolism in peripheral tissues as well as probable inhibition of hypothalamic-pituitary-thyroid axis [9]-[18]. The patterns include low T3 and free T3 with both normal or subnormal T4 during the initial stage of an illness and variable thyroid-stimulating hormone levels ranging from subnormal to elevated depending on outcome of the illness including death or recovery respectively [Table 1]. Low free T4 and normal or subnormal levels are also frequently encountered in outpatients during screening for thyroid dysfunction and may indicate presence of central hypothalamic or hypopituitary hypothyroidism. Simultaneous elevation of reverse T3 is also well documented in euthyroid sick syndrome [1]-[16]. However, the data regarding reverse T3 concentration in central hypothyroidism especially is sparse in children and none in adults [19] [20] [21]. Therefore, we determined reverse T3 in subjects with low free T4 and normal or subnormal TSH levels to assess its utility in distinguishing between central hypothyroidism and euthyroid sick syndrome in adult subjects.

\section{Subjects and Methods}

Serum Free T3 and Reverse T3 concentrations were determined in 78 consecutive adult subjects, 34 men and 44 women with ages, 28 - 69 years with low serum free T4, $0.80 \pm 0.02$ [normal range, $0.89-1.70 \mathrm{mcg} / \mathrm{dl}$ ] and low/normal TSH, $1.29 \pm 0.40$ [normal range, $0.45-4.67 \mathrm{uU} / \mathrm{ml}$ ] concentrations referred

Table 1. Thyroid hormone concentration during acute illness.

\begin{tabular}{ccccccc}
\hline Stages of Illness & T4 & T3 & RT3 & FT4 & TSH & $\Delta$ TSH $^{*}$ \\
\hline I (Mild) & N or $\uparrow$ or $\downarrow$ & $\downarrow$ & $\uparrow$ & $\mathrm{N}$ & $\mathrm{N}$ & $\mathrm{N}$ \\
II (Severe) & $\mathrm{N}$ or $\downarrow$ & $\downarrow \downarrow$ & $\uparrow \uparrow$ & $\mathrm{N}$ & $\mathrm{N}$ & $\downarrow$ \\
III (Critical) & $\downarrow \downarrow$ & $\downarrow \downarrow \downarrow$ & $\uparrow \uparrow \uparrow$ & $\mathrm{N}$ & $\downarrow$ & $\downarrow \downarrow$ \\
IV (Early Recovery) & $\downarrow$ & $\downarrow$ & $\uparrow$ & $\mathrm{N}$ & $\uparrow$ & $\uparrow$ \\
V (Post Recovery & $\mathrm{N}$ & $\mathrm{N}$ & $\mathrm{N}$ & $\mathrm{N}$ & $\mathrm{N}$ & $\mathrm{N}$ \\
\hline
\end{tabular}

$\mathrm{N}=\mathrm{N}$ ormal $\uparrow=$ Increased $\downarrow=$ Decreased $*$ TSH response to TRH stimulation. Reprinted with permission from reference 8 . 
to endocrinology clinic at academic medical center during 12 months, 1/1/2019-12/31/2019. Serum free T4, free T3, TSH and reverse T3 levels were also determined in age matched 35 healthy volunteers, 25 men and 30 women and reassessed at 3 - 6 weeks in subjects in the study group. All determinations were performed in the local clinical laboratory using well established kits using enzymatic assays [Abbot Laboratories, Abbot Park, Illinois]. Inter assay and intrasssay coefficients of variation ranged between 10\% - 15\%. Statistical analyses for comparisons between groups were conducted using Student's " $\mathrm{t}$ " test and ANOVA. All data are reported as Mean \pm SEM.

\section{Results}

In subjects with low free T4 and subnormal or normal TSH levels, reverse T3 determination established two distinct groups: one with subnormal concentrations and the other with supernormal levels [Table 2]. Serum free T3 concentrations varied between subnormal and normal concentrations in both groups established by reverse T3 [Table 2]. Moreover, on reassessment after 3 - 6 weeks, free T4, free T3, TSH and reverse T3 levels normalized in the group with elevated reverse T3 indicative of recovery from "Euthyroid Sick Syndrome". In the other group, reverse T3 remained subnormal while free T4, free T3 and TSH levels remained unchanged suggesting presence of Central Hypothyroidism [Table 3]. Finally, free T4, free T3 and Reverse T3 normalized following therapy with LT4 in subjects deemed to manifest central hypothyroidism [Table 4].

Table 2. Age and serum free T4, free T3, TSH and reverse T3 concentrations in subjects with Euthyroid sick syndrome and central hypothyroidism.

\begin{tabular}{ccccc}
\hline & Normal Subjects & Range & $\begin{array}{c}\text { Euthyroid Sick } \\
\text { Syndrome }\end{array}$ & $\begin{array}{c}\text { Central } \\
\text { Hypothyroidism }\end{array}$ \\
\hline Age (Years) & $48 \pm 4.8$ & $25-71$ & $50 \pm 3.6$ & $47 \pm 4.4$ \\
Free T4 (ug/dl) & $1.26 \pm 0.15$ & $0.89-1.70$ & $0.82 \pm 0.02$ & $0.85 \pm 0.02$ \\
Free T3 (ng/dl) & $3.5 \pm 0.32$ & $2.3-4.2$ & $2.61 \pm 0.23$ & $3.05 \pm 0.18$ \\
TSH (uU/ml) & $3.1 \pm 0.42$ & $0.45-4.67$ & $1.67 \pm 0.38$ & $1.21 \pm 0.50$ \\
Reverse T3 (ng/dl) & $17.6 \pm 2.3$ & $11-26$ & $23.81 \pm 1.2$ & $8.78 \pm 0.55^{*}$ \\
\hline
\end{tabular}

${ }^{\star} \mathrm{p}<0.01$ vs Normal subjects.

Table 3. Serum free T4, free T3, TSH and reverse T3 concentrations in subjects with Euthyroid Sick Syndrome (ESS) and Central Hypothyroidism $(\mathrm{CH})$ at initial determination (Pre) and on reassessment (Post) after 3 - 6 weeks.

\begin{tabular}{ccccc}
\hline & ESS Pre & ESS Post & CH Pre & CH Post \\
\hline Free T4 & $0.82 \pm 0.02$ & $1.28 \pm 0.4^{*}$ & $0.85 \pm 0.02$ & $0.81 \pm 0.03$ \\
Free T3 & $2.61 \pm 0.23$ & $3.56 \pm 0.32^{\star}$ & $3.05 \pm 0.18$ & $2.89 \pm 0.27$ \\
TSH & $1.67 \pm 0.38$ & $2.23 \pm 0.42^{\star}$ & $1.21 \pm 0.50$ & $1.25 \pm 0.43$ \\
Reverse T3 & $23.81 \pm 1.2$ & $14.76 \pm 0.84^{*}$ & $8.78 \pm 0.55$ & $7.79 \pm 0.58$ \\
\hline
\end{tabular}

${ }^{*} \mathrm{p}<0.01$ vs. ESS Pre. 
Table 4. Free T4, Free $\mathrm{T} 3$ and reverse $\mathrm{T} 3$ prior to (Pre $\mathrm{Rx}$ ) and 3 months after administration of Levothyroxine (Post $\mathrm{Rx}$ ).

\begin{tabular}{cccc}
\hline & Free T4 ug/dl & Free T3 ng/dl & Reverse T3 ng/dl \\
\hline Pre Rx & $0.81 \pm 0.03$ & $2.89 \pm 0.27$ & $7.79 \pm 0.58$ \\
Post Rx & $1.34 \pm 0.21^{*}$ & $4.23 \pm 0.45^{*}$ & $18.32 \pm 1.12^{\star}$ \\
\hline
\end{tabular}

${ }^{*} 0.01$ vs. Pre Rx.

\section{Discussion}

Thyroid hormone alterations are well established to occur during an acute or chronic illness including postoperative period as well as following caloric restriction and carbohydrate deprivation despite adequate caloric intake [1]-[15]. During a critical illness, the changes in concentrations of thyroid hormones and TSH continue to evolve depending on survival or recovery [Table 1]. These thyroid hormone changes are labeled "euthyroid sick syndrome". The hallmark of the "syndrome" includes fall in T3, the rise in reverse T3 and both T4 and TSH concentrations remaining in the normal range at the onset of illness. With progression of illness, both the decline in T3 and a rise reverse T3 exacerbate further with lowering of both serum T4 and TSH to subnormal levels. These changes continue the pattern if illness results in death. Alternatively, TSH rises to supernormal levels with onset of recovery. Finally, all these thyroid function tests normalize following a total recovery. These transient changes are attributed to altered thyroid hormone metabolism as well as transient "hypothalamic hypothyroidism" due to impaired release of Thyrotropin releasing hormone [TRH] as well as inhibition of hypothalamic pituitary thyroid axis [10]-[18]. In contrast, persistent central hypothyroidism $[\mathrm{CeH}]$ is a rare disorder caused by reduced generation of $\mathrm{T} 4$ by an otherwise normal thyroid gland due to decreased stimulation by absolute or relatively subnormal circulating TSH induced by decline in synthesis or release of TSH consequential to hypo function of pituitary thyrotrophs [20] [21] [22] [23]. Alternatively, inhibition of synthesis and release of TSH may also be induced by a decline in circulating TRH induced by a disorder of the hypothalamus [20] [21]. Finally, both forms of central hypothyroidism require imaging to ascertain presence of local anatomical abnormalities including tumor, infiltrating or inflammatory disorders.

Both "Euthyroid Sick syndrome" and central hypothyroidism tend to manifest identical laboratory abnormalities including low T4 and/or low T3 and normal or low TSH concentrations. This study demonstrates that elevated reverse T3 on initial determination with return to normal on subsequent testing may indicate presence of "Euthyroid sick syndrome". Alternatively, subnormal reverse T3 noted at initial assessment and remaining low at repeated evaluation may suggest presence of central hypothyroidism. Moreover, normalization of free T4, free T3 and reverse T3 with persistent normal or low TSH on supplementation of LT4 may confirm the diagnosis of central hypothyroidism.

Data regarding reverse T3 concentrations in central or primary hypothyroid- 
ism especially is limited. Low reverse $\mathrm{T} 3$ has been documented in congenital central hypothyroidism in isolated reports [20] [21]. However, reverse T3 concentration in central or primary hypothyroidism in adults is rarely described in the literature [22] [23].

Low T3 and T4 levels with elevated reverse T3 concentrations in "euthyroid sick syndrome" are well established to be secondary to inhibition of monodeiodinase required for conversion of $\mathrm{T} 4$ into $\mathrm{T} 3$ as well as reverse $\mathrm{T} 3$ into diiodothyronine [T2] in nonthyroidal tissues. In contrast, low reverse T3 in central hypothyroidism may be induced by decreased synthesis and release of $\mathrm{T} 4$ by the thyroid gland secondary to hypo function of the pituitary thyrotrophs or TRH generating cells of hypothalamus.

\section{Acknowledgements}

Sarah Exley: Tabulation of the data, statistical analysis and assistance in preparation of the manuscript; no conflict to disclose. No funding information to declare.

Sonal Banzal: Assessment of History and physical exam and patient clinic visit exams, lab data, and preparing draft of manuscript. No conflict to disclose, No funding information to declare.

Udaya Kabadi: Development of hypothesis, design of protocol, supervision of the patient care, and finalization of the manuscript. No conflict to disclose, No funding information to declare.

\section{Conflicts of Interest}

The authors declare no conflicts of interest regarding the publication of this paper.

\section{References}

[1] Kabadi, U.M., Premachandra, B.N. and Maayan, M. (1982) Low Serum $T_{3}$ and Raised Reverse $\mathrm{T}_{3}$ Concentrations in Diabetes Mellitus: Normalization on Improvement in Hyperglycemia. Acta Diabetologica Latina, 19, 233-242. https://doi.org/10.1007/BF02624683

[2] Kabadi, U.M. and Premachandra, B.N. (1983) Serum $T_{3}$ and Reverse $T_{3}$ Levels in Hepatic Cirrhosis: Relation to Hepatocellular Damage and Normalization on Improvement in Liver Dysfunction. The American Journal of Gastroenterology, 78, 750-755.

[3] Kabadi, U.M. and Premachandra, B.N. (1984) Low Triiodothyronine and Raised Reverse Triiodothyronine Levels in Patients over Fifty Years of Age Who Have Type II Diabetes Mellitus: Influence of Metabolic Control, Not Age. Journal of the American Geriatrics Society, 32, 375-379. https://doi.org/10.1111/j.1532-5415.1984.tb02043.x

[4] Kabadi, U.M. (1984) Altered Thyrotropin Secretion in Uncontrolled Type II Diabetes Mellitus and Its Normalization on Attainment of Eumetabolic State. The Journal of Clinical Endocrinology and Metabolism, 59, 521-525.

https://doi.org/10.1210/jcem-59-3-521 
[5] Kabadi, U.M. (1986) Serum $\mathrm{T}_{3}$ and Reverse $\mathrm{T}_{3}$ Concentrations: Indices of Metabolic Control in Diabetes Mellitus. Diabetes Research, 3, 417-421.

[6] Chopra, I.J. (1997) Clinical Review 86: Euthyroid Sick Syndrome: Is It a Misnomer? The Journal of Clinical Endocrinology \& Metabolism, 82, 329-334. https://doi.org/10.1210/jcem.82.2.3745

[7] Kabadi, U.M. (2006) Role of Thyrotropin in Metabolism of Thyroid Hormones in Non-Thyroidal Tissues. Metabolism Clinical \& Experimental, 55, 748-750. https://doi.org/10.1016/j.metabol.2006.01.010

[8] Sharma, S. and Kabadi, U.M. (2008) Euthyroid Sick Syndrome. Primary Care, 14, $1-12$.

[9] Warner, M.H. and Beckett, G.J. (2010) Mechanisms behind the Non-Thyroidal Illness Syndrome: An Update. Journal of Endocrinology, 205, 1-13. https://doi.org/10.1677/JOE-09-0412

[10] Van den Berghe, G. (2014) Non-Thyroidal Illness in the ICU: A Syndrome with Different Faces. Thyroid, 24, 1456-1465. https://doi.org/10.1089/thy.2014.0201

[11] Fliers, E., Bianco, A.C., Langouche, L. and Boelen, A. (2015) Thyroid Function in Critically Ill. The Lancet Diabetes \& Endocrinology, 3, 816-825. https://doi.org/10.1016/S2213-8587(15)00225-9

[12] Lee, S. and Farwell, A.P. (2016) Euthyroid Sick Syndrome. Comprehensive Physiology, 6, 1071-1080. https://doi.org/10.1002/cphy.c150017

[13] Wang, Y.F., Heng, J.F., Yan, J. and Dong, L. (2018) Relationship between Disease Severity and Thyroid Function in Chinese Patients with Euthyroid Sick Syndrome. Medicine (Baltimore), 97, e11756. https://doi.org/10.1097/MD.0000000000011756

[14] Ruiz-Núñez, B., Tarasse, R., Vogelaar, E., et al. (2018) Higher Prevalence of "Low T3 Syndrome" in Patients with Chronic Fatigue Syndrome: A Case-Control Study. Frontiers in Endocrinology (Lausanne), 9, 97-112. https://doi.org/10.3389/fendo.2018.00097

[15] Maiden, M.J. and Torpy, D.J. (2019) Thyroid Hormones in Critical Illness. Critical Care Clinics, 35, 375-388. https://doi.org/10.1016/j.ccc.2018.11.012

[16] Burman, K.D., Dimond, R.C., Wright, F.D., Earll, J.M., Bruton, J. and Wartofsky, A. (1977) Radioimmunoassay for 3,3',5'-L-triiodothyronine (Reverse T3): Assessment of Thyroid Gland Content and Serum Measurements in Conditions of Normal and Altered Thyroidal Economy and Following Administration of Thyrotropin Releasing Hormone (TRH) and Thyrotropin )TSH). The Journal of Clinical Endocrinology \& Metabolism, 24, 660-672. https://doi.org/10.1210/jcem-44-4-660

[17] Bettendorf, M., Schmidt, K.G., Tiefenbacher, U., et al. (1997) Transient Secondary Hypothyroidism in Children after Cardiac Surgery. Pediatric Research, 41, 375-379. https://doi.org/10.1203/00006450-199703000-00012

[18] Kabadi, U.M. (2001) Thyrotropin Dysregulation during a Non-Thyroidal Illness: Transient Hypothalamic Hypothyroidism? Journal of Endocrinological Investigation, 24, 178-182. https://doi.org/10.1007/BF03343839

[19] De Groot, L.J. (2006) Non-Thyroidal Illness Syndrome Is a Manifestation of Hypothalamic-Pituitary Dysfunction, and in View of Current Evidence, Should Be Treated with Appropriate Replacement Therapies. Critical Care Clinics, 22, 57-86. https://doi.org/10.1016/j.ccc.2005.10.001

[20] Klein, A.H., Foley, T.P., Bernard, B., et al. (1978) Cord Blood Reverse T3 in Congenital Hypothyroidism. The Journal of Clinical Endocrinology \& Metabolism, 46, 336-338. https://doi.org/10.1210/jcem-46-2-336 
[21] Faase, E.M., Meacham, L.R., Novack, C.M., et al. (1997) Decreased Reverse T3 Levels in Neonates with Central Hypothyroidism. Journal of Perinatology, 17, 15-17.

[22] Lozanov, B., Vyrbanov, V. and Zakharieva, B. (1982) Thyroid Hormone Level in the Serum in Untreated Hypothyroidism and in Substitution Therapy. Problemy Endokrinologii, 28, 20-25.

[23] Desai, M., Irani, A.J., Patil, K. and Pandya, C. (1984) The Importance of Reverse Triiodothyronine in Hypothyroid Children on Replacement Treatment. Archives of Disease in Childhood, 59, 30-35. https://doi.org/10.1136/adc.59.1.30 